\section{From youthful PMs to presidents who walk tall}

Sir - M. de L. Brooke reasons that British and US voters will elect a leader from an age group that they respect. On the basis of an analysis of the age at which British prime ministers first came to power, he concludes that "voters give the job to somebody whose attributes are honest signals of ability in the society of the day" (Nature 398, 102; 1999). Both reasoning and conclusion are flawed.

First, Brooke fails to ask whether the ages of victorious prime ministers differ significantly from those of their vanquished opponents. The two-party nature of the British and US electoral systems makes this a vital question. If they do not differ significantly, then voters cannot choose on the basis of age - the choice has already been made for them. If they do differ, then we need to know in what direction(s).

Second, it is at least questionable whether people vote for prime ministers at all. There is plenty of psephological evidence to show that it is the political party that commands people's loyalty. This can be demonstrated anecdotally. Winston Churchill was an immensely popular war leader, but he was heavily defeated in the 1945 general election. Jim Callaghan was more popular than Margaret Thatcher, but he lost in 1979. It is also significant that Brooke does not find an age trend in the US system, where there is a more direct relationship between voter and president.

It might be possible to rescue at least a version of Brooke's thesis by shifting the emphasis away from voter choice to party structure. That is, to claim that the reason that prime ministers have become progressively younger in the twentieth century is that there is a perception on the part of the major players in political parties that the voting public has less respect for older people than in the past. But there are still problems. First, the analysis would no longer be founded on a notion of 'honest signals of quality'. And second, it would be to oversimplify the process whereby an élite rises to the top of a party. For example, Margaret Thatcher - in electoral terms, the most successful prime minister of this century - became leader of her party in 1975 in circumstances that had nothing to do with her age (and a lot to do with Sir Keith Joseph's committing political suicide by a speech in Birmingham; and Edward du Cann's withdrawing from the Conservative leadership contest at the last moment). And Tony Blair became leader of the Labour party only after the sudden death of John Smith.

As a philosopher, I frequently try to persuade colleagues of the merits of a sophisticated reductionism. Unfortunately, in this instance, the reductionism is not sophisticated and the conclusions are, therefore, likely to be erroneous. Incidentally, I wonder if your correspondent is aware that every US president elected between 1900 and 1968 was taller than his major opponent.

\section{Jeremy Stangroom}

The Philosophers' Magazine,

98 Mulgrave Road, Sutton, Surrey SM2 6LZ, UK

\section{Reaping the benefits of cropping experiments}

Sir - There is no doubt that intensive agriculture has significant environmental impacts. There is also a widespread belief that 'conventional' agriculture is the problem and 'ecological' methods the solution. David Tilman ${ }^{1}$ discusses a single experiment ${ }^{2}$ that compared legume-based and farmyard manure-based cropping systems with a fertilizer-based one. Can such experiments be used as the basis for general statements about agriculture?

Comparisons of cropping systems often have more of an illustrative than an explanatory value, since there are so many factors differing. There is a risk that the conclusions that can be drawn from comparisons between very different systems are either self-evident or obscure.

In this case, two carbon-exporting systems are compared with a carbonrecycling one (manure). Soils in all treatments received equal amounts of carbon input. But manure input to soil is a more stable carbon source than fresh plant residues. Manure is produced by feeding, for example cattle, and the cattle gain energy from the more accessible carbohydrates, leaving more recalcitrant compounds in the manure. Therefore, it should be no surprise that soil carbon levels over a 15-year period increase more from adding recalcitrant (manure) carbon than from adding carbon in fresh crop residues.

The increase in soil carbon owing to legumes in the crop rotation may partly be due to differences in the quality of crop residues, but may also be due to differences in longevity of the crop, higher water uptake (drier soil gives lower carbon losses) or differences in soil cultivation. Usually, legume or grass leys increase soil carbon compared with annual crops, owing to these factors.

When looking at cumulative nitrate leaching, there was a $50 \%$ higher rate from the fertilizer-based system, although not statistically significant $(P=0.06)$. But the whole difference for the 15-year period is based on the observation that only one year out of the five measured had a higher leaching rate. This is interesting, but there is no attempt to discuss this difference.

Much valuable information can be obtained by comparing different cropping systems in long-term experiments. However, as long as the interpretation is biased and the information provided to the reader is incomplete, conclusions will remain more ideological than scientific. Olof Andrén, Holger Kirchmann,

\section{Olle Pettersson}

Department of Soil Sciences,

Swedish University of Agricultural Sciences, Box 7014, S-75007 Uppsala, Sweden

Tilman replies - Andrén and co-authors express scepticism about the possibility that 'ecological' methods may help solve agricultural pollution ${ }^{2}$, but do not dispute the equality of yields from manured versus fertilized crops. I highlighted ${ }^{1}$ experimental work on 'ecological' farming ${ }^{2}$ not because it offered a definitive solution to agricultural pollution, which it did not do, but because it demonstrated the plausibility of approaches that have been ignored in most conventional research. Any practices that seemingly reduce pollution while maintaining yields and profitability are worthy of study.

Agricultural intensification during the past 35 years has led to a doubling of world grain production, but this required 6.9- and 3.5-fold increases in annual global rates of nitrogen and phosphorus fertilization, respectively, and a doubling of irrigated land ${ }^{3}$. Use of pesticides also increased markedly, with many of these accumulating far from points of application ${ }^{4}$. If these trends presage the future, the next doubling of global food production, expected within 35 years, will require a tripling of nitrogen and phosphorus fertilization and a doubling of irrigation ${ }^{3}$.

Nitrogen and phosphorus losses from agricultural fields are already the major source of nutrient loading into freshwater and nearshore marine ecosystems ${ }^{5}$, and are a major source of terrestrial nutrient loading ${ }^{6}$. This pollution is having serious impacts on non-agricultural ecosystems ${ }^{5-6}$.

Research is needed that pursues all reasonable approaches to this problem. The apparent distrust between conventional and 'ecological' schools of agricultural thought must not blind either side to novel insights, nor slow the development of solutions to a global problem.

\section{David Tilman}

Department of Ecology, Evolution and Behavior, University of Minnesota,

St. Paul, Minnesota 55108, USA

. Tilman, D. Nature 396, 211-212 (1998)

2. Drinkwater, L. E. et al. Nature 396, 262-265 (1998).

3. Tilman, D. Proc. Natl Acad. Sci. USA 96 (in the press, 1999).

4. Blais, J. M. et al. Nature 395, 585-588 (1998).

5. Carpenter, S. et al. Ecol. Applications 8, 559-568 (1998).

6. Vitousek, P. et al. Ecol. Applications 7, 737-750 (1997). 